\title{
OPTIMIZATION OF PRUNER LINEAR MOTOR MAGNETIC SYSTEM
}

\author{
Sergey Antonov \\ Stavropol State Agrarian University, Russia \\ antonov_serg@mail.ru
}

\begin{abstract}
Gardening is one of the most promising branches of agriculture. Intensive planting of new orchards requires rapid development of technologies and tools to support the harvesting process. The formation of the garden's harvest largely depends on modern and high-quality pruning of tree branches. An analysis of the tool base for garden care showed that $80 \%$ of horticultural enterprises use hand tools. Pneumatic and hydraulic tools are used by $15 \%$ of enterprises. Only $5 \%$ of households use electric pruning shears when pruning trees. These secateurs are manufactured by Electrocoup, Bosch, and Makita. The domestic instrument is represented by the developments of the 80s and 90s of the last century. Therefore, there is a need to develop modern pruning shears based on a linear electric motor. Their advantages are high reliability, low noise level and low power consumption. This is especially important since tree pruning takes place over large areas and the presence of large energy sources reduces the pruner's mobility. The linear electric drive is not used in existing pruning shears. This is due to the lack of a theory of designing magnetic systems for hand-held electrified tools. Chain methods for calculating magnetic systems have a high error, which does not allow determining the optimal design at the stage of calculations. This is primarily due to the redistribution of the magnetic flux from the stator through the air gap to the motor armature. The use of modern computer programs (ElCut), using the finite element method for calculations, will allow at the design stage to obtain the optimal design of the magnetic system with a given accuracy. Modeling and optimization of the magnetic system of the electric motor will reveal the most effective direction for the development of pruning shears for pruning trees based on a linear electric motor. The aim of the study is to optimize the magnetic system of the linear electric motor of the pruner. The optimal design of the magnetic system allows increasing the armature pulling force up to $84.35 \mathrm{~N}$.
\end{abstract}

Keywords: linear electric motor, magnetic system, magnetizing coil, magnetic flux, magnetic induction, gardening, secateurs.

\section{Introduction}

Reforming modern domestic horticulture should take into account such factors as reducing labor intensity and energy consumption of production processes, improving the processes of orchard set-up and gardening, as well as harvesting the resulting crop. The efficiency of these processes depends on the level of mechanization, electrification and automation. One of the most time consuming processes is the detailed pruning of tree branches. Up to $80 \%$ of enterprises use manual labor for pruning. This affects both the efficiency of work and the cost of the resulting product. Farms using electrified tools account for only 5\%. These are tools from Makita, Bosch, Karsher, Electrocoup, etc. [1; 2].

Known works of scientists [3-13], in which the authors studied various problems in the design, manufacture and operation of linear electric motors. The main directions of research in these works were: analysis of the characteristics of linear electric motors; suppression of pulsations of the armature thrust force; characteristics of tubular linear electric motors.

As a drive for cutting blades, DC motors are used, which have a number of disadvantages. The use of linear electric motors will eliminate some of these disadvantages.

Linear electric motors are classified into DC motors (Fig. 1.), asynchronous, synchronous, electromagnetic and hybrid motors.

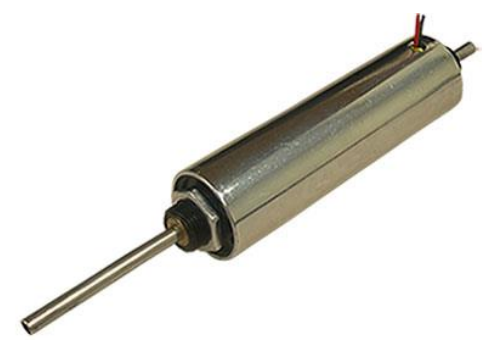

Fig. 1. Linear electric motor DDLM-019-070-01

In some cases, the use of linear electric motors is not advisable due to the high specific rate of the active materials usage per $1 \mathrm{~kW}$ of generated power $\left(20 \mathrm{~kg} \cdot \mathrm{kW}^{-1}\right)$. However, for a hand tool, this 
indicator in some cases can be two times lower than for an electric motor of rotary motion. At the same time, the most important advantage of using a linear electric motor is the absence of a gearbox and motion converter, which reduce reliability and increase vibration and noise [14-18].

\section{Materials and methods}

The proposed design of a linear electric motor will make it possible to create a new level of handheld electrified tool. The linear electric motor contains a stator (1), consisting of a magnetic housing (2), a magnetizing coil (3), a non-magnetic frame (4), a first magnetic pole (5), a second magnetic pole (6), a bolt (7), a third magnetic pole (8), bolt (9) and non-magnetic insert (10). The armature (11) contains a first magnetic circuit (12), a second magnetic circuit (13), a non-magnetic sleeve (14), a non-magnetic rod (15). The device also has a spring (16), a washer (17) and a nut (18) (Fig. 2). The operating principle of a linear electric motor is presented in [19].

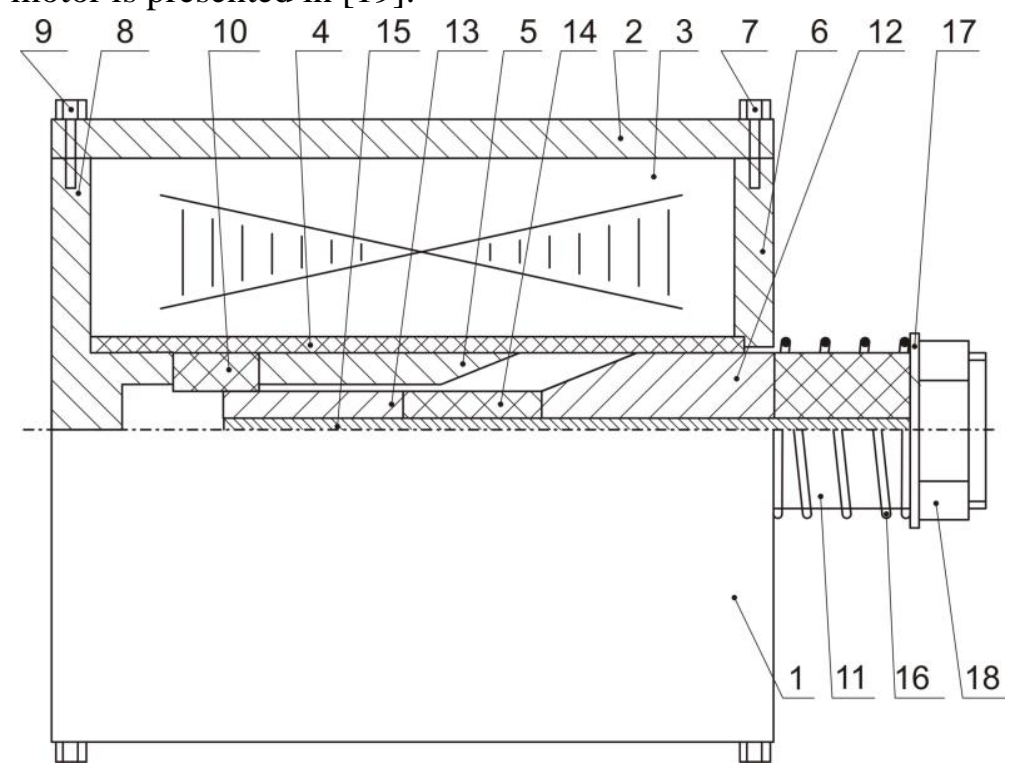

Fig. 2. Linear electric motor

The improvement of electrical machines is associated with the optimization of the design parameters. The use of modern materials in the design of the magnetic system makes it possible to increase the electric machine efficiency. This is the case only for already developed electric motors. When designing electric machines of a new generation or operating principle, it is necessary to conduct research to optimize the design of the magnetic system. The operating principle of a linear electric motor is based on the use of the magnetic saturation effect of the magnetic circuit sections and pushing the magnetic flux towards the armature. The passage of this magnetic flux through the armature leads to the appearance of an electromagnetic force. The anchor [20] moves under the influence of this force.

It is known from the theory of the magnetic field that lines of magnetic force emanating from the magnetic system elements are perpendicular to its surface. Therefore, when optimizing the magnetic system of a linear electric motor, it is necessary to determine the design parameters that affect the distribution of magnetic fluxes. One of the parameters is the bevel angle of the first magnetic pole $\alpha$ (5) and the bevel angle of the first magnetic circuit $\beta$ (12). Another parameter is the length of the nonmagnetic insert L (10) (Fig. 3.).

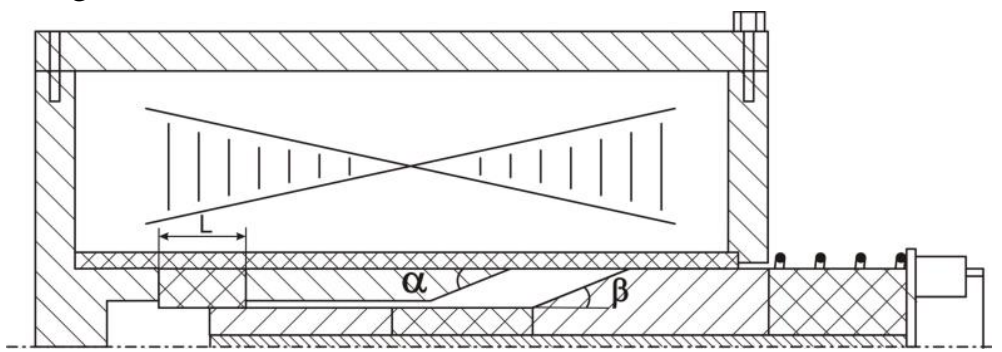

Fig. 3. Optimization parameters of the magnetic system of a linear electric motor 
There are several types of calculation for the magnetic system parameters. The use of the chain method in the calculation of complex structures leads to a decrease in the calculation accuracy, due to the presence of air gaps of small length, compared to the coil dimensions and the length of the field line. The calculation by the finite difference method allows to obtain a result with a given accuracy and for any point of the calculated area.

The value of the magnetic potential of any point $\mathrm{A}$ of the investigated space can be expressed through the value of the node potential $0\left(\mathrm{~A}_{0}\right)$ on the $\mathrm{x}$-axis using the Taylor's series (Formula 1):

$$
A=A_{0}+\left(\frac{\partial A}{\partial x}\right)_{0}\left(x-x_{0}\right)+\frac{1}{2 !}\left(\frac{\partial^{2} A}{\partial x^{2}}\right)_{0}\left(x-x_{0}\right)^{2}+\frac{1}{3 !}\left(\frac{\partial^{3} A}{\partial x^{3}}\right)_{0}\left(x-x_{0}\right)^{3}+\ldots
$$

For nodes located in areas where the field describes the Laplace equation for a symmetric (Formula 2) and asymmetric (Formula 3 ) stars, the equation will have the form:

$$
\begin{gathered}
A_{1}+A_{2}+A_{3}+A_{4}-4 A_{0}+h^{2} W=0 \\
2\left[\frac{A_{1}}{p(1+p)}+\frac{A_{2}}{q(1+q)}+\frac{A_{3}}{(1+p)}+\frac{A_{4}}{(1+q)}-\left(\frac{1}{p}+\frac{1}{q}\right) A_{0}\right]+h^{2} W=0 .
\end{gathered}
$$

The ElCut software application allows to create a model of the magnetic system and perform calculations with high accuracy.

\section{Results and discussion}

When solving the problem of optimizing the magnetic system of a linear electric motor, we use the ElCut software application. For the correct solution of the problem, it is necessary to set the conditions and parameters of the structural elements properly. After that, it is required to build a mesh of finite elements (Fig. 4.).

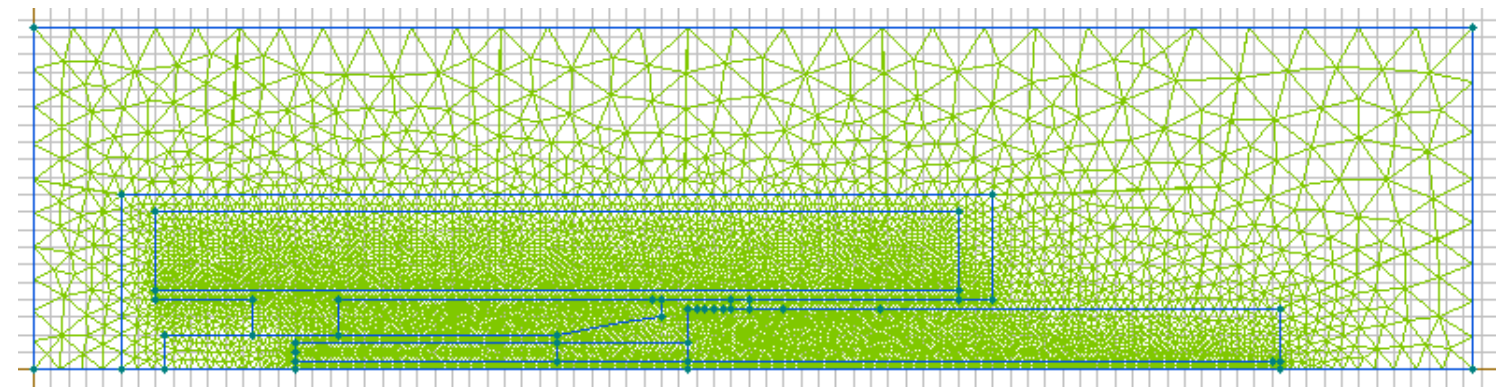

Fig. 4. Finite element meshing

As a result of solving the problem, a magnetic system of a linear electric motor with a color picture of the magnetic induction and the distribution of magnetic fluxes over its elements is obtained (Fig. 5.).

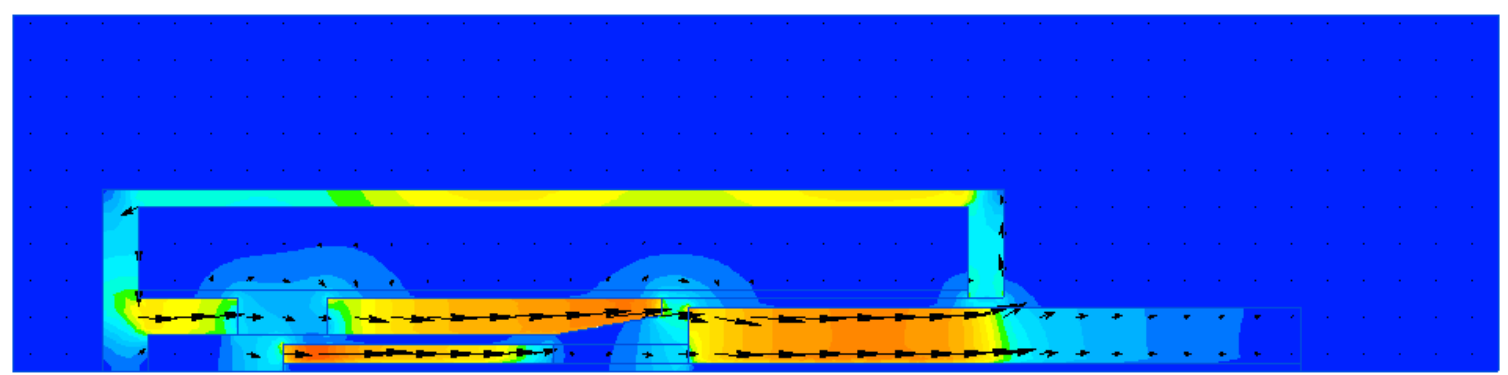

Fig. 5. Calculation result of the magnetic system of a linear electric motor

As a result of mathematical modeling of a linear electric motor, we obtain the results of the armature thrust force for such parameters of the magnetic system, as the bevel angle of the first magnetic pole $(\alpha$ from $10^{\circ}$ to $90^{\circ}$, with a step of $10^{\circ}$ ), the bevel angle of the first magnetic circuit $\left(\beta\right.$ from $10^{\circ}$ to $90^{\circ}$, with a step of $10^{\circ}$ ) and the length of the non-magnetic insert ( $\mathrm{L} 5 \mathrm{~mm}, 10 \mathrm{~mm}, 15 \mathrm{~mm}$ ). The results obtained are presented in Tables 1, 2, 3 . 
Thrust force (electromagnetic force) acting on the armature $(N)$ with a length of non-magnetic insert $(L) 5 \mathrm{~mm}$

\begin{tabular}{|c|c|c|c|c|c|c|c|c|c|}
\hline \multirow{2}{*}{$\begin{array}{c}\text { Bevel angle } \\
\text { of the first } \\
\text { magnetic } \\
\text { circuit } \beta,^{\circ}\end{array}$} & \multicolumn{9}{|c|}{ Bevel angle of the first magnetic pole $\alpha,^{\circ}$} \\
\hline & 10 & 20 & 30 & 40 & 50 & 60 & 70 & 80 & 90 \\
\hline 10 & 28.42 & 27.04 & 26.72 & 25.44 & 24.17 & 23.62 & 22.53 & 21.47 & 20.70 \\
\hline 20 & 31.72 & 29.63 & 27.43 & 25.78 & 25.37 & 24.84 & 22.99 & 22.03 & 20.97 \\
\hline 30 & 35.18 & 30.17 & 29.19 & 26.93 & 26.14 & 25.78 & 23.75 & 22.97 & 21.31 \\
\hline 40 & 42.75 & 31.25 & 30.25 & 27.73 & 26.78 & 26.42 & 24.44 & 23.62 & 22.46 \\
\hline 50 & 15 & 34.45 & 31. & & 27.65 & 27 & 25.72 & 24.70 & 22.99 \\
\hline 60 & 1 & 39.72 & 32.28 & 29 & 28.19 & 27.59 & 26.37 & 25.27 & 23.76 \\
\hline 70 & 1.33 & 41.26 & 33.16 & 29.73 & 28.94 & 28.04 & 26.91 & 25.75 & 24.10 \\
\hline 80 & 4.04 & 42.17 & 3572 & 31.15 & 29.25 & 28.62 & 27.25 & 26.02 & 24.48 \\
\hline 90 & 57.26 & 44.95 & 36.18 & 31.42 & 29.77 & 28.97 & 27.72 & 26.34 & 24.83 \\
\hline
\end{tabular}

Thrust force (electromagnetic force) acting on the armature $(N)$

Table 2 with a length of non-magnetic insert $(L) 10 \mathrm{~mm}$

\begin{tabular}{|c|c|c|c|c|c|c|c|c|c|}
\hline $\begin{array}{c}\text { Bevel angle } \\
\text { of the first } \\
\text { magnetic } \\
\text { circuit } \boldsymbol{\beta} \mathbf{,}^{\mathbf{0}}\end{array}$ & $\mathbf{1 0}$ & $\mathbf{2 0}$ & $\mathbf{3 0}$ & $\mathbf{4 0}$ & $\mathbf{5 0}$ & $\mathbf{6 0}$ & $\mathbf{7 0}$ & $\mathbf{8 0}$ & $\mathbf{9 0}$ \\
\cline { 2 - 11 } & & & & & & & & & \\
\hline 10 & 55.52 & 49.64 & 42.45 & 41.17 & 39.94 & 39.73 & 38.16 & 34.78 & 34.76 \\
\hline 20 & 60.90 & 52.66 & 44.35 & 42.63 & 40.37 & 40.19 & 38.39 & 36.87 & 34.77 \\
\hline 30 & 65.55 & 52.83 & 45.61 & 43.14 & 41.59 & 40.25 & 39.52 & 37.13 & 36.02 \\
\hline 40 & 65.67 & 53.58 & 46.44 & 43.31 & 42.84 & 40.47 & 39.45 & 37.21 & 36.38 \\
\hline 50 & 65.74 & 55.67 & 47.54 & 44.09 & 43.29 & 40.59 & 39.78 & 38.36 & 37.70 \\
\hline 60 & 69.92 & 56.11 & 47.87 & 44.58 & 43.68 & 41.59 & 40.31 & 38.36 & 37.79 \\
\hline 70 & 72.35 & 56.80 & 48.77 & 45.13 & 44.05 & 42.63 & 40.97 & 39.05 & 37.85 \\
\hline 80 & 76.65 & 58.34 & 49.21 & 46.43 & 44.43 & 42.69 & 41.24 & 39.33 & 37.98 \\
\hline 90 & 83.53 & 62.86 & 51.29 & 46.97 & 44.93 & 43.18 & 41.98 & 39.57 & 38.33 \\
\hline
\end{tabular}

Thrust force (electromagnetic force) acting on the armature $(N)$

Table 3 with a length of non-magnetic insert $(L) 15 \mathrm{~mm}$

\begin{tabular}{|c|c|c|c|c|c|c|c|c|c|}
\hline $\begin{array}{c}\text { Bevel angle } \\
\text { of the first } \\
\text { magnetic } \\
\text { circuit } \boldsymbol{\beta} \boldsymbol{,}^{\mathbf{0}}\end{array}$ & $\mathbf{1 0}$ & $\mathbf{2 0}$ & $\mathbf{3 0}$ & $\mathbf{4 0}$ & $\mathbf{5 0}$ & $\mathbf{6 0}$ & $\mathbf{7 0}$ & $\mathbf{8 0}$ & $\mathbf{9 0}$ \\
\cline { 2 - 11 } & & & & & & & & & \\
\hline 10 & 56.23 & 51.22 & 44.07 & 42.65 & 40.05 & 39.62 & 38.32 & 35.09 & 34.92 \\
\hline 20 & 62.40 & 53.75 & 45.35 & 43.73 & 41.27 & 40.53 & 38.73 & 37.26 & 35.03 \\
\hline 30 & 66.71 & 54.01 & 46.93 & 44.15 & 42.57 & 40.76 & 39.92 & 37.42 & 3529 \\
\hline 40 & 67.02 & 55.27 & 47.75 & 44.96 & 43.44 & 41.07 & 40.05 & 37.95 & 35.84 \\
\hline 50 & 67.93 & 56.01 & 48.26 & 46.04 & 44.27 & 41.24 & 40.17 & 38.20 & 36.19 \\
\hline 60 & 72.15 & 58.24 & 49.33 & 47.12 & 45.09 & 42.19 & 40.41 & 38.74 & 37.01 \\
\hline 70 & 73.41 & 58.96 & 50.01 & 48.37 & 45.98 & 42.75 & 40.93 & 39.11 & 37.26 \\
\hline 80 & 77.87 & 59.33 & 51.29 & 49.15 & 46.34 & 43.04 & 41.27 & 39.31 & 37.90 \\
\hline 90 & 84.35 & 63.15 & 53.72 & 50.43 & 47.26 & 43.51 & 41.73 & 39.67 & 38.07 \\
\hline
\end{tabular}

The results of modeling the magnetic system of a linear electric motor, given in Tables 1, 2, 3, give the result, the thrust force that appears at the anchor. This force is required to drive the actuator. The 
obtained values of this force for various parameters of the magnetic system can be used in the future, when calculating the kinematic diagram of transmission of energy to the actuator of a hand-held electrified tool.

After analyzing the calculated data, we can say that the magnitude of the electromagnetic force of the armature created by the magnetic field increases with an increase in the length of the non-magnetic insert and the bevel angle of the first magnetic circuit.

\section{Conclusions}

1. The use of a linear electric motor will help simplify the design of handheld electrified tools, improve the energy efficiency and reduce vibration and noise.

2. Optimization of the magnetic system parameters of a linear electric motor showed that, with an increase in the bevel angle of the first magnetic circuit $(\beta)$ from $10^{\circ}$ to $90^{\circ}$, at a fixed bevel angle of the first magnetic pole $\left(\alpha=10^{\circ}\right)$, the armature thrust force increases, for $L=5 \mathrm{~mm}$ from 28.42 to $57.26 \mathrm{~N}$, for $L=10 \mathrm{~mm}$ from 55.52 to $83.53 \mathrm{~N}$, and for $L=15 \mathrm{~mm}$ from 56.23 to $84.35 \mathrm{~N}$. The most effective design turned out to be a magnetic system with the parameters $\alpha=10^{\circ}, \beta=90^{\circ}$ and $L=15 \mathrm{~mm}$, the electromagnetic force is $84.35 \mathrm{~N}$ (Tables $1,2,3$ ).

\section{References}

[1] Hedrick U.P. Cyclopedia of Hardy Fruits. New York: The MacMillan Company, 1922. 370 pp.

[2] Csanády E., Magoss E. Mechanics of Wood Machining. 2-nd ed. Springer-Verlag Berlin Heidelberg, 2013. 199 p.

[3] Wang J., Jewell G.W., Howe D. A general framework for the analysis and design of tubular linear PM machines, IEEE Trans., MAG-35(2), 1999, pp. 1986-2000.

[4] Chapman S. Electric Machinery Fundamentals. 5th Edition. - USA: McGraw-Hill Science, 2005. $708 \mathrm{p}$.

[5] Duy V.H., Dao T.T., Zelinka I., Kim S.B., Phuong T.T. (eds.) AETA 2017 - Recent Advances in Electrical Engineering and Related Sciences: Theory and Application. Springer, 2018. 1086 p.

[6] Wang J., Howe D. Tubular modular PM machines equipped with quasi-Halbach magnetized magnets - Part I + II, IEEE Trans., MAG-41(9), 2005, pp. 2470-2489.

[7] Krop D.C.J., Lomonova E.A., Vandenput A.J.A., Application of Schwarz-Cristoffel mapping to PM linear motor analysis, IEEE Trans., MAG-44(3), 2008, pp. 352-359.

[8] Zhu Y.-W., Cho Y.-H. Thrust ripple suppression of PM linear synchronous motor, IEEE Trans., MAG-43(6), 2007, pp. 2537-2539.

[9] Zheng P., Chen A., Thelin P., Arshad W.M., Sadarangani Ch. Research on a tubular longitudinal flux PM linear generator used for free-piston energy converter, IEEE Trans., MAG-43(1), 2007, pp. 447-449.

[10] Prudell J., Stoddard M., Amon E., Brekken T.K.A., von Jouanne A. A PM tubular linear generator for ocean wave energy conversion, IEEE Trans., IA-46(6), 2010, pp. 2392-2400.

[11] Niu S., Ho S.L., Fu W.N. Performance analysis of a novel magnetic-geared tubular linear PM machine, IEEE Trans., MAG-47(10), 2011, pp. 3598-3601.

[12] Holehous R.C., Atallah K., Wang J. Design and realization of a linear magnetic gear, IEEE Trans., MAG-47(10), 2011, pp. 4171-4174.

[13] Wang J., Atalah K., Wang W. Analysis of a magnetic screw for high force density linear electromagnetic actuators, IEEE Trans., MAG-47(10), 2011, pp. 4477-4480.

[14] Тавасиев Р.М. Средства малой механизации для плодовых насаждений крестьянских (Фермерских) хозяйств (Means of small-scale mechanization for fruit plantations of peasant (farmer) farms): diss. ... doct. tech. sciences. Vladikavkaz, 2009. 277 p. (In Russian)

[15] Туриев О.И. Разработка и обоснование основных параметров обрезчика ветвей для крестьянских (Фермерских) хозяйств (Development and justification of the main parameters of the cutter branches for peasant (farm) farms): diss. ... cand. tech. sciences. Vladikavkaz, 1999. 162 p. (In Russian)

[16] Нейман В.Ю. Основы построения и развитие теории импульсных линейных электромагнитных двигателей $\mathrm{c}$ повышенными энергетическими показателями (Fundamentals of the construction and development of the theory of pulsed linear electromagnetic 
motors with increased energy performance): diss. ... doct. tech. sciences. Novosibirsk, 2004. 387 p. (In Russian)

[17] Antonov S., Nikitenko G., Grinchenko V., Molchanov A., Avdeeva V. Electromechanical secateurs based on a linear electric motor and determination of the cutting force of branches of fruit trees. Engineering for rural development, Jelgava Latvia, 2018, pp. 514-518.

[18] Antonov S., Nikitenko G., Linear electric motor for handheld electrified tools used in gardening. Engineering for rural development, Jelgava Latvia, 2019, pp. 804-807.

[19] Antonov S., Nikitenko G., Simulation of linear electric motor for electromechanical pruner. Proceeding of 7th International Conference on "Trends in Agricultural Engineering 2019", 2019. Prague, Czech Republic, 2019, pp. 40-44.

[20] Antonov S., Nikitenko G. Lopper for trimming trees driven by linear electric. Engineering for rural development, Jelgava Latvia, 2020. pp. 833-837. 